Natalia Pires de Vasconcelos

Mandado de Segurança ou Ministério da Saúde? Gestores, procuradores e respostas institucionais à judicialização

TESE DE DOUTORADO

Orientador: Professor Dr. Marcos Paulo Verissimo

UNIVERSIDADE DE SÃO PAULO

FACULDADE DE DIREITO

São Paulo-SP

2018 

Natalia Pires de Vasconcelos

\section{Mandado de Segurança ou Ministério da Saúde? \\ Gestores, procuradores e respostas institucionais à judicialização}

Tese de Doutorado apresentada à Banca Examinadora do Programa de Pós-Graduação em Direito, da Faculdade de Direito da Universidade de São Paulo, como exigência parcial para obtenção de título de Doutora em Direito, na área de concentração de Direito do Estado, Subárea de Concentração: Direito Constitucional, sob orientação do Professor Dr. Marcos Paulo Verissimo.

UNIVERSIDADE DE SÃO PAULO

FACULDADE DE DIREITO

São Paulo-SP

2018 
Autorizo a reprodução e divulgação total ou parcial deste trabalho, por qualquer meio convencional ou eletrônico, para fins de estudo e pesquisa, desde que citada a fonte.

Natalia Pires de, Vasconcelos

Mandado de Segurança ou Ministério da Saúde? Gestores, procuradores e respostas institucionais à judicialização / Vasconcelos Natalia Pires de; orientador Marcos Paulo Verissimo -- São Paulo, 2018. 267.

Tese (Doutorado - Programa de Pós-Graduação em Direito do Estado) Faculdade de Direito, Universidade de São Paulo, 2018.

1. Judicialização da saúde. 2. Políticas Públicas. 3. Respostas Institucionais. 4. Direito à Saúde. 5. Burocracias. I. Verissimo, Marcos Paulo, orient. II. Título. 
Vasconcelos, Natalia Pires. Mandado de Segurança ou Ministério da Saúde? Gestores, procuradores e respostas institucionais à judicialização. 267 folhas, Doutorado - Faculdade de Direito, Universidade de São Paulo, 14 de janeiro de 2018.

\section{Resumo}

O Sistema Único de Saúde, ou SUS, enfrenta ao menos 40.000 ações judiciais por ano. A maior parte dessas ações é promovida por indivíduos requerendo medicamentos e tratamentos não cobertos pela política de saúde. O Judiciário decide a favor dos demandantes na grande maior parte dos casos, determinando que a administração pública atenda aos pedidos dentro de prazo exíguos e sob pena sanções fortes. Além de gastos crescentes, esta litigância em massa afeta a própria organização interna da política, não só por alterar a distribuição de recursos financeiros dentro do sistema, mas por exigir das secretarias de saúde o estabelecimento de inteiras "políticas de gestão" da judicialização, dotadas de funcionários, sistemas e estruturas físicas próprias, em atuação em rede com órgãos externos à administração pública, como o Judiciário, Defensorias Públicas, Ministérios Públicos e Procuradorias.

Este é o tema desta tese. Por meio do estudo de quatro casos - São Paulo, Rio de Janeiro, Santa Catarina e Rio Grande do Sul - exploro as estratégias de gestão da judicialização da saúde, de modo compreender o papel de diferentes atores em um movimento pouco tradicional de elaboração de políticas públicas. Adoto como hipótese que gestores atuam de forma estratégica, buscando alternativas que lhes permitam não só cumprir as decisões judiciais de forma mais eficiente, mas ao mesmo tempo reduzir seu impacto sobre o funcionamento da política como um todo. Não somente, aprendem enquanto agem, em um movimento que constrói alternativas e as revisa enquanto são implementadas. Suas estratégias tentam responder a dois desafios impostos pela judicialização: o grande volume de ações que exigem respostas rápidas e resolutivas, sob pena de sanções fortes e mais custosas; e o caráter interinstitucional do fenômeno, que demanda dos gestores uma atuação fora de suas organizações, em espaços judiciais ou jurídicos e em articulação com atores destes espaços, com sua linguagem própria e formas específicas de legitimação.

Deste mapeamento, constatei que as burocracias tanto das secretarias estaduais como do sistema de justiça atuam em três frentes para gerir a judicialização - buscam reduzir o número 
de ações judiciais a partir de estratégias administrativas ou pré-processuais, atuam sobre as demandas em curso, gerindo o cumprimento e qualificando a defesa processual, e buscam articulações meta-processuais, estabelecendo espaços de diálogo e interação com outros atores envolvidos diretamente com o fenômeno. Nestas três frentes estabelecem políticas públicas que criam, implementam e revisam. Não somente, a atuação em rede gera especialização em direção ao mundo jurídico - as Secretarias "inflam” ou desmembram suas assessorias e consultorias

jurídicas especialmente para estabelecer fluxos de trabalho e canais de comunicação mais eficientes com o mundo jurídico. Este movimento é marcado por uma articulação específica - a atuação conjunta de procuradores de Estado e gestores de saúde.

\section{PALAVRAS CHAVES}

JUDICIALIZAÇÃO DA SAÚDE, GESTÃO, ESTRATÉGIAS, POLÍTICAS PÚBLICAS. 
Vasconcelos, Natalia Pires. Mandado de Segurança ou Ministério da Saúde? Gestores, procuradores e respostas institucionais à judicialização. 267 pages, Doctorate - School of Law, University of São Paulo, January 14, 2018.

\begin{abstract}
Judicial decisions questioning the health care policy are extremely common in Brazil, estimated at over 40,000 lawsuits per year. Most cases consist of individual claims requesting specific medicine and treatments that are not covered by the Brazilian universal health care policy follow cost/benefit analysis. Courts usually rule in favor of claimants and order the state to provide such requests within short deadlines and under the threat of strong sanctions. Most of these decisions are given by state-level courts and are based only on the constitutional right to healthcare.
\end{abstract}

This massive healthcare litigation has growing effects on budgetary planning. Recent reports show that complying with judicial decisions on health has led to a growing expenditure of almost 1 billion Reais in 2014-2015. However, increasing costs are not the sole issue. Since judicial decisions require compliance from any and all levels of government, policy organization, and division of responsibilities between different federal levels is largely compromised.

The large literature on the matter is highly focused on what happens inside Courts, providing little evidence of the following steps taken by public health care officials to comply with these decisions or mitigate their impact. By focusing on policy formulation and implementation, my research undertakes the task of mapping what happens after Courts decide. Policy officials are perceived not only as reactive actors. Besides responding to each judicial decision individually, they are learn-by-doing while creating and implementing policy strategies to lessen or prevent the different effects of intense judicialization. Assessing four Brazilian States' responses (Sao Paulo, Rio de Janeiro, Santa Catarina and Rio Grande do Sul), my research unfolds the governance of the health litigation, through the creation of new organs, systems, procedures and a different class of bureaucrats. These responses vary in each State, but they have been consistent and can be divided into three different groups: policy strategies that 
are administrative and previous to any lawsuit, aiming at solving the patient's problem before they get to Courts; legal strategies, created and implemented to provide more technical arguments to the State's lawsuit defense while addressing compliance with judicial decisions; and larger responses that stablish interinstitutional committees that formalize open channels of communication and interaction between policy officials and legal officers. These strategies gain more stability and policy form as healthcare secretariats become more "justice-like". Their legal consultants gain new responsibilities, staff and power and establish working networks between actors from the healthcare policy and from the justice system, especially state lawyers. The interaction and partnership between policy officials and state lawyers appears as another key explanatory variable to most of these strategies. Both bureaucracies develop a common language that connects healthcare and law. In addition, they coordinate their actions before, during and after lawsuits.

\section{KEY WORDS}

HEALTH LITIGATION, GOVENANCE, STRATEGIES 


\section{Agradecimentos}

Esta pesquisa é o resultado de reflexões que surgiram de estudos comuns e conversas informais com muitos professores, amigos e colegas, além de todos os entrevistados que cederam parte considerável do seu tempo para me explicar passos elementares do seu dia-a-dia, trabalho e trajetória. Nomeio aqui apenas algumas destas pessoas, por falta de espaço, porque escrevo estes agradecimentos a dois dias do prazo de submissão e, principalmente, porque a lista é bastante longa, o que torna este trabalho uma peça a muitas mãos. Primeiramente agradeço ao meu orientador, Marcos Paulo Verissimo que acompanha meu trabalho desde a graduação em direito e sempre manteve suas portas abertas, com sábios conselhos sobre a academia e a vida. Agradeço aos professores Conrado Hubner Mendes e Virgilio Afonso da Silva, pelo trabalho constante em orientar um grupo de alunos de pós-graduação de forma coesa e pouco ortodoxa, quebrando velhos hábitos da tão velha academia e se aventurando em um processo ainda em curso de criar um espaço igualitário, sério e interessante de trabalho e discussão acadêmica. Agradeço também aos professores Rogerio Arantes e Vanessa Elias de Oliveira pelas tantas conversas, aulas e trabalhos conjuntos que me permitiram amadurecer muitas das ideias aqui apresentadas, sem perder o bom humor e ao som de Despacito. À Vanessa agradeço ainda a parceria constante e as noções de burocracia e políticas públicas que informam esta tese.

Agradeço de forma mais detida ao professor e amigo Daniel Wang, com quem tenho a oportunidade de trabalhar desde o fim da Escola de Formação na sbdp. A maior parte desta tese é tributária da sua orientação, ideias, ideais e experiência com o tema. Não somente, a minha trajetória acadêmica é em grande medida orientada pela dele. Sua disposição em engajar horizontalmente estudantes de diferentes níveis acadêmicos em um projeto comum e dividir igualmente o elemento "braçal" da pesquisa empírica, sem ele mesmo se distinguir em termos de carga de trabalho e importância de ideias, tem sido uma conduta inspiradora para toda a equipe que trabalha atualmente em um projeto sob sua coordenação. Não somente, demonstra que a academia pode ser sim um espaço horizontal, democrático e participativo.

Este trabalho não teria acontecido sem a disposição de muitas pessoas em diferentes Estados e instituições. Agradeço aqui aos entrevistados, juízes, promotores, gestores e 
procuradores de Santa Catarina, São Paulo, Rio Grande do Sul e Rio de Janeiro. Não nomeio todos eles, para preservar sua confidencialidade, mas apenas aqueles que entrevistei pessoalmente e que me permitiram citar expressamente seus nomes ao longo desta tese: Leticia Simon, Sinezio Vieira, Luiz Duarte, José Luiz Souza, Paula Sue, Ana Luiza Chieffi, Bruno Terra, Maria Amelia Santos de Carvalho, Mauricio Carlos Araujo Ribeiro, Flavio Badaró, Daniel Cardoso, Maria Teresa Agostin, Caroline Cabral e Daniel Buffone. Agradeço especialmente a Fernanda Terrazas, Leticia Simon, Sinezio Vieira, Luiz Duarte, Jose Luiz Souza, Ana Chieffi e Paula Sue pela interlocução próxima, amigável e horizontal. Encontrei neles e em muitos dos entrevistados verdadeiros militantes do SUS, servidores que acreditam em um sistema único, seguro, gratuito e universal e que lutam por uma sociedade mais justa e igualitária. As imprecisões e impressões desta tese sobre suas falas e práticas são unicamente de minha responsabilidade.

Agradeço aos meus amigos e colegas da pós-graduação em direito e do grupo de Constituição, Política e Instituições, especialmente a Rafael Bellem de Lima, Fabio Cesar Oliveira, Luiza Correa, Carolina Marinho, Rafael Nunes, Clio Randomysler, Artur Pericles, Cecilia Barreto e Guilherme Jardim. Agradeço ainda aos amigos que a FFLCH me trouxe, especialmente ao professor Glauco Peres da Silva, à Luiza Ferreira Lima, Sergio Simoni, Tiago Borges, San Romanelli, Rodrigo Martins, Thiago Moreira, Marcos Paulo de Lucca Silveira, Alexia Aslan, Pedro Ernesto de Castro e Graziele Silotto. Agradeço também aos meus colegas do grupo de pesquisa coordenado por Daniel Wang, sobretudo Fernanda Mascarenhas, Ana Arruda e Edson Joaquim. Registro aqui a minha profunda gratidão a Fabio Oliveira, pelos conselhos e recomendações de última hora, à Rafael Bellem de Lima, pela motivação, deboches e troca de ideias diário, e à Carolina Marinho e Fernanda Mascarenhas, pelo esforço hercúleo em me ajudar com a revisão e conteúdo deste trabalho nos 45 minutos do segundo tempo.

Agradeço também aos interlocutores recentes junto ao INSPER, especialmente aos professores Marcos Lisboa, Paulo Furquim e à amiga Maria Clara Morgulis. Espero que por meio de sua revisão crítica eu possa corrigir e aprimorar muitas das ideias econômicas desta tese. 
Sou profundamente grata à Faculdade de Direito e à Faculdade de Filosofia, Letras e Ciências Humanas, da Universidade de São Paulo e ao programa Fox Fellowship da Universidade de Yale. Em Yale descobri interlocutores e amigos que participaram ativamente da construção de muitas das ideias desta tese. Agradeço, especialmente ao professor Ben Cashore, à Julia Muravnik, Sudha Tiwari, Joanne Tan, Agnete Aslaug, Israfil Boyaci, Alexandra Jönsson e Juliana Cesarino Alvim. Agradeço ainda ao grupo de estudos Global Health Justice Partnership, também de Yale, e especialmente a professora Amy Kapczynski. Deixo aqui meus agradecimentos mais detidos a Victor Louzon, Gilad Abiri e Satveer Kaur (minha querida amiga e "esposa") por seu apoio atento, constante e irrestrito, que supera fronteiras, língua e diferenças culturais.

Agradeço, por fim, a João Otavio e sua família, pelo por todo o apoio durante os longos anos de mestrado e doutorado; às minha amigas antigas, Deborah, Julia e Maria Cecilia, pelo contato constante, mesmo longe, e a demonstração das muitas formas de boa vida; a meus avós, Inês e Jurandir, pela dedicação e exemplo de resiliência; a meus irmãos, Fabiana e Eduardo, pelo apoio, por nunca perguntarem quando finalmente deixarei a faculdade e começarei a "trabalhar" e pelas boas, profundas e leves conversas, ao som de Kendrick Lamar; e especialmente, à minha mãe, Maria Monica, pois sem seu amor e trabalho com saúde, e sua dedicação constante aos seus pacientes e filhos, nem os ideais existiriam. 


\section{Sumário}

Capítulo 1: Introdução, o problema e a metodologia................................................................. 5

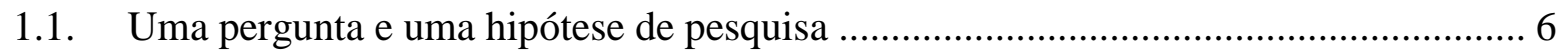

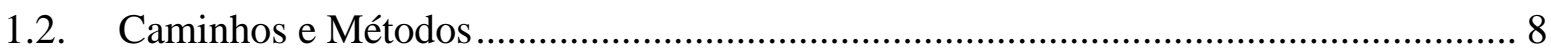

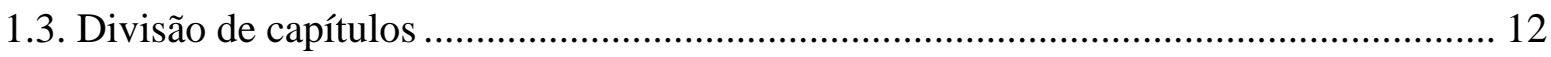

Capítulo 2: O SUS e a judicialização da saúde...................................................................... 15

2.1. O sistema de saúde brasileiro ............................................................................... 15

2.1.1. O desenho constitucional e legal do SUS .............................................................. 21

2.1.2. Financiamento público da saúde …………………………………………..... 24

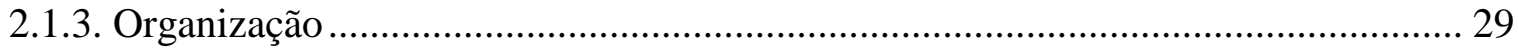

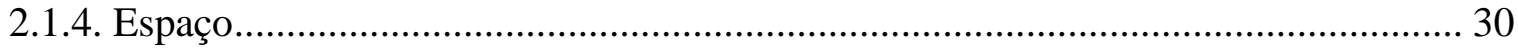

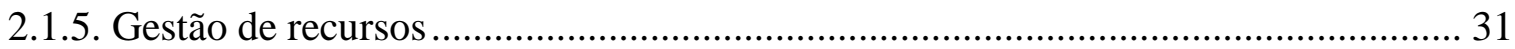

2.1.6. Serviços e Assistência Farmacêutica........................................................................ 32

2.2. Judicialização da saúde: um fenômeno global e brasileiro ............................................. 37

2.3. As respostas institucionais gerais à judicialização ......................................................... 50

2.3.1. Da gestão meta-processual via CNJ: Recomendações, Comitês Estaduais e NATs51

2.3.2. Da gestão processual via STF e STJ: Repercussão Geral e Recursos Repetitivos.. 60

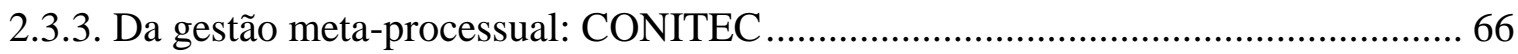

Capítulo 3: O perfil geral da judicialização em quatro Estados ................................................... 72

3.1. Alguns dados gerais sobre a judicialização em três capitais - São Paulo, Florianópolis e

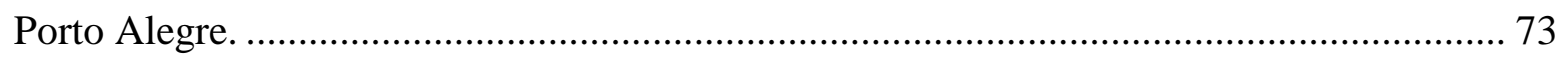

3.2. Perfil da judicialização no Estado de São Paulo: ............................................................ 80

3.2.1. As respostas institucionais de São Paulo ................................................................. 88

3.3. Perfil da judicialização Santa Catarina ........................................................................ 112 
3.3.1. As respostas institucionais de Santa Catarina...................................................... 118

3.4. Perfil da judicialização Rio Grande do Sul ................................................................ 138

3.4.1 As respostas institucionais do Rio Grande do Sul ................................................ 144

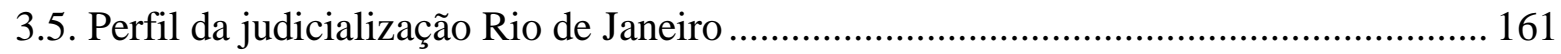

3.5.1. As respostas institucionais do Rio de Janeiro ........................................................ 166

Capítulo 4: Política pública, burocracias e judicialização ....................................................... 189

4.1. Elaborando políticas públicas - conceito, atores, processos e judicialização................ 190

4.2. Burocracias de rua, de médio escalão e a elaboração de políticas públicas.................. 215

4.3. Aprendizado em burocracias: prática e colaboração ………………………………..... 226

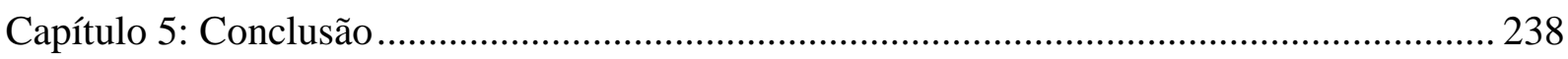

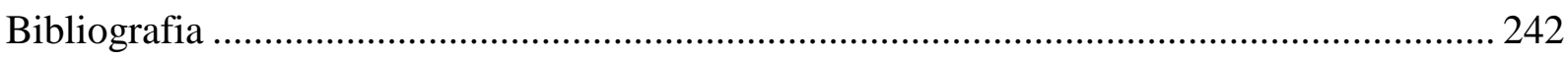




\section{Capítulo 1: Introdução, o problema e a metodologia}

O Sistema Único de Saúde, ou SUS, enfrenta ao menos 40.000 ações judiciais por ano (FERRAZ, 2011). A literatura sobre o tema aponta que a maioria dessas ações é promovida por indivíduos requerendo medicamentos e tratamentos não cobertos pela política de saúde. O Judiciário decide a favor dos demandantes na grande maior parte dos casos, determinando que a administração pública atenda aos pedidos dentro de prazo exíguos e sob pena sanções fortes, como multas, prisão de funcionários públicos, bloqueio ou sequestro de recursos orçamentários da política.

Essa judicialização massiva da saúde importa em um impacto orçamentário crescente sobre a política pública de saúde. Relatórios recentes indicam que os gastos com a judicialização no âmbito federal atingiram o patamar de 1,2 bilhões de reais entre 2014 e 2015 (BRASIL, 2017). Estados e Municípios enfrentam custos proporcionalmente ainda maiores, na medida em que ações judiciais são propostas indistintamente contra todos os entes da federação, a despeito da divisão de competências na prestação de serviços de saúde dentro do SUS. Além de gastos crescentes, esta litigância em massa afeta a própria organização interna da política, não só por alterar a distribuição de recursos financeiros dentro do sistema, mas por exigir das secretarias de saúde o estabelecimento de inteiras "políticas de gestão" da judicialização, dotadas de funcionários, sistemas e estruturas físicas próprias, em atuação em rede com órgãos não governamentais, como o Judiciário, Defensorias Públicas, Ministérios Públicos e Procuradorias. Este é o tema desta tese. Por meio do estudo de quatro casos - São Paulo, Rio de Janeiro, Santa Catarina e Rio Grande do Sul - exploro as estratégias de gestão da judicialização da saúde, de modo compreender o papel de diferentes atores em um movimento pouco tradicional de elaboração de políticas públicas.

Esta tese pretende demonstrar que estes atores - gestores e membros do sistema de justiça - não são apenas reativos à judicialização, mas agem de forma estratégica e prospectiva, organizando fluxos mais ou menos eficientes para atender as demandas judiciais, enquanto enxergam a própria judicialização como um "problema” a ser endereçado por políticas públicas processuais, pré-processuais e meta-processuais. Um dos argumentos chave para entender estas políticas está na articulação mais ou menos intensa entre gestores de saúde responsáveis pelo 
cumprimento de decisões judiciais e procuradores do Estado, competentes para realizar a defesa processual das secretarias face o Judiciário. Enquanto gestores trazem à mesa seu conhecimento técnico e linguagem própria da saúde pública - "olha a gente sempre falava para gente é MS é Ministério da Saúde não é mandado de segurança, o cidadão é paciente para a gente, a gente quer cuidar" (Entrevista Gestora SP 4), procuradores "traduzem" esta linguagem em termos cada vez menos "jurídicos” em um movimento dinâmico de aprendizado mútuo e cooperação "Ah, interesse de agir, citar Carnelutti e o escambau e não sei o que lá. Não, você tem que falar porque que ele buscou o Judiciário, se há na prateleira da UBS lá da casa dele. Isso é muito mais eficaz" (Entrevista Procurador SP 2).

\subsection{Uma pergunta e uma hipótese de pesquisa}

Este trabalho começou com um questionamento geral: como as burocracias da administração pública respondem à judicialização? Considerando que este é um fenômeno com mais de 20 anos e que atinge a gestão federal, estadual e municipal da saúde, é de se esperar que os gestores se comportem de forma não só espontânea e pontual diante das demandas judiciais, mas que assumam a atuação do Judiciário sobre a política como um dado da realidade do SUS e passem também a atuar de forma prospectiva, traçando estratégias de gestão. Assim, da

pergunta de pesquisa "como as burocracias da administração pública respondem a judicialização?” parti da seguinte hipótese de pesquisa, que pretendo testar ao longo dos próximos capítulos: gestores atuam de forma estratégica, buscando alternativas que lhes permitam não só cumprir as decisões judiciais de forma mais eficiente, mas ao mesmo tempo reduzir seu impacto sobre o funcionamento da política como um todo. Não somente, aprendem enquanto agem, em um movimento que constrói alternativas e as revisa enquanto são implementadas. Esta hipótese, portanto, assume que os gestores são atores racionais, que aprendem sobre sua realidade e agem sobre ela. Espera ainda que suas estratégias tentem responder a dois desafios impostos pela judicialização: o grande volume de ações que exigem respostas rápidas e resolutivas, sob pena de sanções fortes e mais custosas; e o caráter interinstitucional do fenômeno, que demanda dos gestores uma atuação fora de suas organizações, em espaços judiciais ou jurídicos e em articulação com atores destes espaços, com sua linguagem própria e formas específicas de legitimação. 
Os estudos sobre a judicialização da saúde no Brasil em geral não se voltam ao que ocorre uma vez que as decisões judiciais são deferidas. Apesar de partirem de diferentes áreas do conhecimento, especialmente do direito, das ciências sociais e da saúde pública, em sua maior parte voltam-se ao perfil dos litigantes, a compatibilidade dos medicamentos e serviços requeridos com os protocolos e listas do SUS e ao comportamento de juízes, especialmente os argumentos utilizados para deferir os pedidos. Uma pequena parcela dos trabalhos, que analisa os impactos da judicialização sobre a política de saúde, atenta-se para os efeitos disruptivos das decisões judiciais sobre as contas públicas e sobre a organização de competências do SUS. Mapeiam, assim, a judicialização como uma "questão/problema", mas não analisam o que acontece uma vez que esta "questão/problema" também é constada e internalizada pela administração pública ou mesmo pelo Judiciário. Esta tese é tributária dos poucos trabalhos (especialmente WANG, 2015; OLIVEIRA e NORONHA, 2011; VENTURA, 2012) que se voltam a este momento pós-decisões judiciais e buscam compreender as repostas institucionais à judicialização a partir da perspectiva das burocracias envolvidas.

Para responder à pergunta geral de pesquisa e testar sua hipótese, este trabalho tem um tom amplamente exploratório, na medida em que busca mapear as estratégias de gestão e lhes conferir sentido. Deste mapeamento, como veremos nos próximos capítulos, constatei que as burocracias tanto das secretarias estaduais como do sistema de justiça atuam em três frentes para gerir a judicialização - buscam reduzir o número de ações judiciais a partir de estratégias administrativas ou pré-processuais, atuam sobre as demandas em curso, gerindo o cumprimento e qualificando a defesa processual, e buscam articulações meta-processuais, estabelecendo espaços de diálogo e interação com outros atores envolvidos diretamente com o fenômeno. Nestas três frentes estabelecem políticas públicas que criam, implementam e revisam. Não somente a atuação em rede gera especialização em direção ao mundo jurídico - as Secretarias "inflam" ou desmembram suas assessorias e consultorias jurídicas especialmente para estabelecer fluxos de trabalho e canais de comunicação mais eficientes com o mundo jurídico. Este movimento é marcado por uma articulação específica - a atuação conjunta de procuradores de Estado e gestores de saúde.

Para dar sentido a estas respostas, mobilizo tanto a literatura de judicialização da saúde e os dados que levantam para caracterizar a "questão/problema" que as estratégias de gestão 
visam atacar, como a literatura sobre formulação de políticas públicas e da atuação de burocracias neste processo. $\mathrm{O}$ que veremos são burocracias que se assemelham ao que a literatura denomina de burocracias de médio escalão elaborando políticas públicas enquanto as implementam, em um processo contínuo de articulação com atores do direito, especialmente procuradores de Estado.

\subsection{Caminhos e Métodos}

O estudo do problema desta tese se iniciou dentro de um esforço coletivo de pesquisa coordenado por Daniel Wang para tentar compreender o papel de evidências técnicas nos argumentos mobilizados dentro do processo por demandantes, Estado e juízes. Como um time de pesquisadores visitamos três dos quatro Estados analisados nesta tese para coletar evidências documentais em amostras estatisticamente significativas da judicialização da saúde contra Secretarias Estaduais. Visitamos as Procuradorias Gerais do Estado na cidade de São Paulo e em Porto Alegre, e a Secretaria de Saúde de Santa Catarina, em Florianópolis. O processo de coleta de documentos in loco me permitiu entrar em contato com o dia a dia destes espaços e destes burocratas e minha pesquisa de doutorado, que visava especialmente analisar os padrões de cumprimento de decisões judiciais pelos Estados assumiu um caminho diferente, na medida em que eu constava, pela vivência e conversas com estes atores, a multiplicidade e complexidade das estratégias criadas para gerir a judicialização. Além de sistemas informatizados criados ou atualizados especificamente para gerir o fluxo de cumprimento e a defesa processual de ações conta o Estado, observei uma constante comunicação entre gestores e procuradores do Estado em um padrão curioso: gestores traçando observações sobre normas processuais e os limites do direito à saúde e procuradores se referindo a protocolos clínicos e efetividade de terapias prescritas ou constantes das listas do SUS. A forma ou qualidade desta interação variava entre Estados, mas em todos era possível verificar que gestores e procuradores atuavam em parceria na construção de argumentos híbridos, da saúde pública e do direito, para a instrução de contestações e recursos. Não somente estes atores trabalhavam em órgãos particularmente criados para gerir decisões judiciais e tomavam a judicialização como sua atividade diária. Estas observações de campo redefiniram meu objeto de estudo e dão, em grande medida, o tom e orientação deste trabalho. 
Para mapear as estratégias de gestão da judicialização aliei os dados disponibilizados pela literatura e relatórios oficiais das Procuradorias do Estado, Secretarias, Tribunal de Contas da União e Conselho Nacional de Justiça, com os dados da pesquisa coletiva em andamento, coordenada por Daniel Wang, Steven Hoffman e Virgilio Afonso da Silva (a que me refiro, daqui para frente, como "a pesquisa em andamento coordenada por Wang et al.”). Além destes dados, conduzi 27 entrevistas em 4 Estados que registram altos índices de judicialização e são amplamente referidos pela literatura tanto pelo impacto que demandas judiciais vieram a ter sobre suas políticas estaduais de saúde como pelas estratégias que encontraram para administrar estas demandas: Rio de Janeiro, Santa Catarina, São Paulo e Rio Grande do Sul. Três destes quatro Estados já faziam parte do recorte da pesquisa em andamento coordenada por Wang et al.. Neles o acesso a entrevistados e dados das decisões judiciais foi facilitado por esta porta de entrada.

Para estabelecer quem seriam os entrevistados, comecei pelos gestores e procuradores com os quais estabeleci contato direto no campo, entrevistando, em um segundo momento, os gestores e procuradores que eles sugeriam, caminhando, assim, pelas redes de referência destes atores até atingir um certo nível de saturação em termos de novas informações sobre as políticas e sobre a judicialização nestes Estados. Por este método de "bola de neve", por certo, as falas e opiniões dos entrevistados não têm representação estatística em termos da posição média de atores em posições similares entre Estados ou mesmo dentro deles. Ainda assim, me permitiu traçar um quadro compreensivo destas políticas de gestão da judicialização e apreender algumas formas de comunicação e sentido compartilhados por estes atores em rede.

Todos os entrevistados e entrevistadas consentiram a gravação da entrevista e seu uso pela presente tese. O consentimento foi formalizado por Termo de Confidencialidade em todas as entrevistas presenciais. Nas entrevistas por telefone optei pelo regime que mais protege os entrevistados e entrevistadas e não divulgo seus nomes ao longo da tese, apenas cargo e órgão dos quais fazem parte. Mesmo para os entrevistados e entrevistadas que consentiram a publicação expressa de seus nomes apenas divulgo-os em tabela de um Anexo eletrônico, que identifica os entrevistados que desejaram ser identificados. Ademais, optei por não disponibilizar a transcrição integral das entrevistas como anexo físico da tese, também para respeitar a privacidade dos entrevistados e entrevistadas no tempo. Transcrevo trechos, ao longo 
do texto, e disponibilizo as transcrições editadas pelos entrevistados e entrevistadas no $\underline{\text { Anexo }}$ eletrônico $^{1}$. Assim, caso os entrevistados e entrevistadas desejem, no futuro, retirar seu consentimento em relação ao uso de seus nomes, suas falas e vivência, posso excluir estas entrevistas deste anexo. As entrevistas foram conduzidas entre julho e dezembro de 2017, tiveram em média 40 minutos e se estruturaram a partir de um modelo semiaberto, organizado apenas em torno de tópicos de discussão que pudessem deixar os entrevistados livres para argumentar sobre (i.) suas trajetórias, (ii.) sua interação com atores do sistema de justiça e suas (iii.) impressões sobre a judicialização do Estado.

Tabela 1: Entrevistados no Rio de Janeiro, órgãos, cargos e formação

\begin{tabular}{|c|c|c|c|c|c|}
\hline ESTADO & ORGAO & $\begin{array}{c}\text { NOME NA } \\
\text { TESE }\end{array}$ & CARGO & CONTATO & FORMAÇÃO \\
\hline $\mathrm{RJ}$ & PGE-RJ & $\begin{array}{l}\text { Procurador } \\
\text { RJ } 1\end{array}$ & Procurador da PG-16 & presencial & $\begin{array}{l}\text { formação } \\
\text { jurídica }\end{array}$ \\
\hline $\mathrm{RJ}$ & JUD/NAT & Juíza RJ & $\begin{array}{l}\text { Juíza Federal titular de } \\
\text { uma vara especializado } \\
\text { em matéria de saúde; } \\
\text { Coordenadora do } \\
\text { Comitê Estadual da } \\
\text { Saúde do CNJ do RJ. }\end{array}$ & presencial & $\begin{array}{l}\text { formação } \\
\text { jurídica }\end{array}$ \\
\hline RJ & SESDEC-RJ & Gestor RJ 2 & $\begin{array}{l}\text { Consultor Jurídico da } \\
\text { SESDEC-RJ }\end{array}$ & presencial & $\begin{array}{l}\text { formação } \\
\text { jurídica }\end{array}$ \\
\hline $\mathrm{RJ}$ & SESDEC-RJ & Gestor RJ 4 & $\begin{array}{c}\text { Coordenador do NAT- } \\
\text { JUS RJ }\end{array}$ & presencial & farmacêutico \\
\hline $\mathrm{RJ}$ & SESDEC-RJ & Gestora RJ 1 & Coordenadora da CRLS & $\begin{array}{l}\text { presencial e } \\
\text { telefônico }\end{array}$ & enfermeira \\
\hline $\mathrm{RJ}$ & PGE-RJ & $\begin{array}{l}\text { Procurador } \\
\text { RJ } 2\end{array}$ & $\begin{array}{l}\text { Procurador Chefe da } \\
\text { PG16, especializada em } \\
\text { saúde }\end{array}$ & presencial & $\begin{array}{l}\text { formação } \\
\text { jurídica }\end{array}$ \\
\hline $\mathrm{RJ}$ & $\begin{array}{l}\text { CADJ/SESDEC- } \\
\text { RJ }\end{array}$ & Gestora RJ 3 & $\begin{array}{l}\text { Coordenadora da CADJ } \\
\text { (Central de Atendimento } \\
\text { de Demandas Judiciais), } \\
\text { SESDEC-RJ }\end{array}$ & $\begin{array}{l}\text { presencial e } \\
\text { telefônico }\end{array}$ & $\begin{array}{l}\text { formação } \\
\text { jurídica }\end{array}$ \\
\hline
\end{tabular}

Fonte: Elaboração própria a partir das entrevistas conduzidas.

\footnotetext{
1 Todos os documentos que fazem parte desta pesquisa, bem como a transcrição das entrevistas e matriz das planilhas encontram-se na pasta online, de acesso apenas para consulta: https://drive.google.com/drive/folders/1Zx1SkzSP5IaP5-kwXPzLVQ_JCTMKzC6U?usp=sharing
} 
Tabela 2: Entrevistados no Rio Grande do Sul, órgãos, cargos e formação

\begin{tabular}{cccccc}
\hline ESTADO & ORGAO & $\begin{array}{c}\text { NOME NA } \\
\text { TESE }\end{array}$ & CARGO & CONTATO & FORMAÇÃo \\
\hline RS & PGE-RS & $\begin{array}{c}\text { Procurador RS } \\
3\end{array}$ & $\begin{array}{c}\text { Membro do Conselho } \\
\text { Superior da Procuradoria- } \\
\text { Geral do Estado, antigo } \\
\text { procurador do NARAS- } \\
\text { RS, Capital }\end{array}$ & telefônico & $\begin{array}{c}\text { formação } \\
\text { jurídica }\end{array}$ \\
\hline RS & SES-RS & Gestor RS 1 & $\begin{array}{c}\text { Coordenador da } \\
\text { Assessoria Jurídica da } \\
\text { SES-RS }\end{array}$ & telefônico & formação \\
jurídica
\end{tabular}

Fonte: Elaboração própria a partir das entrevistas conduzidas.

Tabela 3: Entrevistados em Santa Catarina, órgãos, cargos e formação

\begin{tabular}{|c|c|c|c|c|c|}
\hline ESTADO & ORGAO & $\begin{array}{l}\text { NOME NA } \\
\text { TESE }\end{array}$ & CARGO & CONTATO & FORMAÇÃO \\
\hline $\mathrm{SC}$ & $\begin{array}{l}\text { SES-SC } \\
\text { (COJUR) }\end{array}$ & Gestora SC 1 & $\begin{array}{c}\text { assiste técnica COJUR- } \\
\text { SES/SC }\end{array}$ & presencial & $\begin{array}{c}\text { formação } \\
\text { jurídica }\end{array}$ \\
\hline $\mathrm{SC}$ & $\begin{array}{l}\text { SES-SC } \\
\text { (COMAJ) }\end{array}$ & Gestor SC 2 & $\begin{array}{c}\text { coordenador Comaj até } \\
2017-\text { SES/SC }\end{array}$ & presencial & $\begin{array}{c}\text { formação } \\
\text { jurídica }\end{array}$ \\
\hline $\mathrm{SC}$ & PGE-SC & $\begin{array}{c}\text { Procurador SC } \\
2\end{array}$ & $\begin{array}{l}\text { ex-consultor jurídico } \\
\text { SES/SC até junho de } \\
2017\end{array}$ & presencial & $\begin{array}{l}\text { formação } \\
\text { jurídica }\end{array}$ \\
\hline $\mathrm{SC}$ & SES-SC & Gestora SC 3 & $\begin{array}{c}\text { servidora da COMAJ, } \\
\text { equipe técnica }\end{array}$ & $\begin{array}{l}\text { presencial e } \\
\text { telefônico }\end{array}$ & nutricionista \\
\hline $\mathrm{SC}$ & SES-SC & Gestora SC 5 & $\begin{array}{l}\text { Diretora de Assistência } \\
\text { Farmacêutica }\end{array}$ & presencial & farmacêutica \\
\hline $\mathrm{SC}$ & MP-SC & Promotora SC & $\begin{array}{l}\text { Coordenadora-Adjunta do } \\
\text { Centro de Apoio } \\
\text { Operacional dos Direitos } \\
\text { Humanos e Terceiro } \\
\text { Setor, MP-SP }\end{array}$ & presencial & $\begin{array}{l}\text { formação } \\
\text { jurídica }\end{array}$ \\
\hline
\end{tabular}




\begin{tabular}{cccccc}
\hline SC & SES-SC & Gestora SC 4 & $\begin{array}{c}\text { servidora da COMAJ, } \\
\text { equipe técnica }\end{array}$ & $\begin{array}{c}\text { presencial e } \\
\text { telefônico }\end{array}$ & farmacêutica \\
\hline SC & PGE-SC & $\begin{array}{c}\text { Procurador SC } \\
4\end{array}$ & $\begin{array}{c}\text { Procurador-Chefe da } \\
\text { PGE-SC, Criciúma, } \\
\text { NARAS Criciúma }\end{array}$ & telefônico & $\begin{array}{c}\text { formação } \\
\text { jurídica }\end{array}$ \\
\hline SC & PGE-SC & Procuradora & Procuradora integrante do & telefônico & formação \\
jurídica
\end{tabular}

Fonte: Elaboração própria a partir das entrevistas conduzidas.

Tabela 4: Entrevistados em São Paulo, órgãos, cargos e formação

\begin{tabular}{|c|c|c|c|c|c|}
\hline ESTADO & ORGAO & $\begin{array}{l}\text { NOME NA } \\
\text { TESE }\end{array}$ & CARGO & CONTATO & FORMAÇÃO \\
\hline SP & SES-SP & Gestora SP 4 & $\begin{array}{l}\text { ex-coordenadora da } \\
\text { CODES }\end{array}$ & presencial & farmacêutica \\
\hline SP & PGE-SP & $\begin{array}{c}\text { Procurador SP } \\
1 \\
\end{array}$ & $\begin{array}{l}\text { Procurador chefe da PJ8, } \\
\text { PGE/SP }\end{array}$ & presencial & $\begin{array}{l}\text { formação } \\
\text { jurídica }\end{array}$ \\
\hline SP & $\begin{array}{l}\text { CODES- } \\
\text { SESSP }\end{array}$ & Gestora SP 1 & $\begin{array}{l}\text { Coordenadora da } \\
\text { CODES-SES/SP }\end{array}$ & presencial & $\begin{array}{l}\text { enfermeira e } \\
\text { formação } \\
\text { jurídica }\end{array}$ \\
\hline SP & $\begin{array}{l}\text { CODES- } \\
\text { SESSP }\end{array}$ & Gestor SP 2 & $\begin{array}{l}\text { Diretor Técnico da } \\
\text { CODES-SES/SP }\end{array}$ & presencial & farmacêutico \\
\hline SP & $\begin{array}{l}\text { CODES- } \\
\text { SESSP }\end{array}$ & Gestor SP 3 & $\begin{array}{l}\text { Assessor técnico - } \\
\text { CODES/SES-SP }\end{array}$ & presencial & medico \\
\hline SP & PGE-SP & $\begin{array}{c}\text { Procurador SP } \\
2\end{array}$ & $\begin{array}{l}\text { Procurador da PJ8 - } \\
\text { especializada em saúde }\end{array}$ & presencial & $\begin{array}{l}\text { formação } \\
\text { jurídica }\end{array}$ \\
\hline
\end{tabular}

Fonte: Elaboração própria a partir das entrevistas conduzidas.

Além das entrevistas, relatórios oficiais, dados da pesquisa coordenada por Wang et al. e da literatura, a exposição a seguir se vale de documentos oficiais, como normas e termos de cooperação e das informações disponibilizadas de forma pública pelos sítios eletrônicos dos órgãos da saúde e das procuradorias do Estado. Sempre que foi possível, os relatos sobre as experiências de gestão narrados nas entrevistas foram confrontados com os dados disponibilizados por estas outras fontes.

\subsection{Divisão de capítulos}

A exposição a seguir se divide em três longos capítulos. No primeiro apresento o SUS e a judicialização da saúde, na tentativa de estabelecer aspectos gerais do problema da 
judicialização. Como veremos, o SUS é um sistema complexo e a política de saúde não se resume ao SUS, sendo também bastante "privatizada”. A judicialização da saúde, por outro lado, é um fenômeno global e também bastante brasileiro. Ainda que o país se insira em tendências mais gerais e, especialmente, latino-americanas de litigância em saúde, o fenômeno também tem suas peculiaridades locais, dadas não só pelo volume de ações judiciais, mas sua descentralização em face de um sistema único e público, o que diferencia a nossa experiência das colombiana e argentina.

O capítulo 2 busca os dados mais atuais para retratar a judicialização em nível federal e no nível mais agregado possível para Estados e Municípios, desafio que alguns autores enfrentaram mas que, em geral, é pouco bem-sucedido, dada a dificuldade de integrar fontes e, novamente, a própria descentralização do fenômeno. De um quadro geral, passamos as suas respostas institucionais também gerais, especialmente promovidas pelo STF e CNJ, mas também pelo Ministério da Saúde via CONITEC. A apresentação destas respostas, neste formato, é bastante tributária do estudo de Wang (2015), que realizou um esforço semelhante.

Do SUS, sua judicialização e as respostas institucionais, passamos ao capítulo 3, onde a maior parte das contribuições desta pesquisa se insere. Neste capítulo reconstruo o perfil da judicialização nos quatro Estados - São Paulo, Santa Catarina, Rio de Janeiro e Rio Grande do Sul, as respostas institucionais encontradas para enfrentar a judicialização. Como veremos, estas respostas são locais, adequadas à forma como a judicialização se colocou no Estado, mas também apresentam tendências gerais, como a busca por soluções pré-litigio. Uma outra característica comum é a articulação entre procuradores do Estado e gestores. Como veremos, estes atores são a linha de frente das decisões judiciais contra o Estado, elaborando sua defesa e operacionalizando o cumprimento. Neste processo, eles se aproximam, trocam, se comunicam, e começam a agir de forma estratégica. Muitas das respostas institucionais à judicialização do Estado nascem dessa interação e dependem dela para ter efetividade.

Das respostas institucionais estaduais, passamos ao capítulo 4, que propõe uma releitura destas respostas como de fato políticas públicas, ou seja, medidas do governo em ação, atuando sobre uma "questão/problema" social relevante. Neste capítulo, reconstruo a literatura sobre políticas públicas e sobre o papel de burocracias na sua formulação. Recupero as experiências apresentadas no capítulo 3 e apresento mais informações sobre as duas burocracias-chave que 
tanto criam quanto operam esta rede de respostas institucionais à judicialização: gestores que lidam especificamente com o cumprimento de decisões judiciais e procuradores do Estado. Por fim, na Conclusão, recupero as observações mais gerais dos três capítulos e traço algumas considerações finais. 


\section{Capítulo 5: Conclusão}

Como vimos, a judicialização da saúde tem efeitos disruptivos e redistributivos relevantes sobre a política pública de saúde em nível federal e estadual. Apresentei apenas alguns dados esparsos sobre a judicialização nos municípios, mas a literatura já apontou que estes são talvez os que enfrentam o maior impacto relativo sobre suas contas e organização (WANG al, 2014). Ainda assim, a judicialização representa uma realidade para a política pública de saúde como um todo há mais de 20 anos e os dados atuais não demonstram qualquer indício de que ela deixará de existir no médio prazo.

Com isso, verificando a hipótese de que gestores são atores que utilizam as informações que detêm, aprendem com suas práticas e agem de forma estratégica e prospectiva, observei que ao menos nos quatro Estados analisados existe um movimento das secretarias em atuar em diferentes frentes para conter a judicialização potencial e amenizar o impacto da judicialização corrente. Estas estratégias configuram políticas públicas elaboradas por gestores em rede com atores do sistema de justiça e importam em adaptações nos trabalhos de todos os envolvidos, com especial impacto sobre a organização das secretarias.

Como vimos, estas “inflam” suas consultorias e assessorias jurídicas ou as desmembram e especializam a gestão de demandas judiciais em relação às administrativas. Neste movimento, incorporam uma lógica de gestão de processos em massa, padronizam e uniformizam sua atuação sobre a maior parte das ações e agem de forma mais agregada e estratégica para ações de alto impacto.

As alterações dentro da Secretaria ocorrem em concomitância com sua atuação para fora do órgão, estabelecendo redes de contato e parcerias com atores do sistema de justiça, especialmente procuradores do Estado. Depois das suas próprias consultorias e assessorias jurídicas internas, as PGEs são o primeiro e mais natural elo das SESs com o mundo do direito. São os advogados do governo e, em dois dos três Estados acima, também ocupam as assessorias jurídicas das secretarias por meio de agentes setoriais. Nada mais natural que advogados estejam alinhados com os interesses de seus clientes e busquem a melhor forma de representa-los processualmente. Esta parceria, contudo, transcende o ambiente judicial ou de consultoria caso a caso. Também procuradores se movimentam para fora do seu âmbito de atuação "normal" e “jurídico”. Não só buscam formas de tornar suas defesas mais técnicas, especializando unidades 
para o tratamento separado das demandas de saúde, mas também se qualificam, buscando informações ou valendo-se de pareceres técnicos elaborados por profissionais da saúde (das secretarias, em geral), mas que devem ser inteligíveis tanto a eles quanto a juízes.

Uma das gestoras citadas no capítulo 3 (Gestora SP 4) comparou o fluxo de trabalho sobre a judicialização com a atuação de profissionais de saúde em hospitais, diferenciando as ações mais urgentes ou custosas das demais e lhes imprimindo um tratamento diferenciado em relação a massa de demandas. Esta aproximação entre a gestão das ações judiciais e das urgências hospitalares não é de todo trivial. De fato, observamos este duplo movimento, das secretarias ao mundo do direito, e das procuradorias ao mundo da saúde, mediado por ressignificações do que é técnico ou legitimo. O técnico pertence ao mundo da expertise da saúde, e não do direito. É, contudo, um técnico que não advém apenas da opinião de um médico ou profissional, mas que foi sancionado pelas esferas mais altas do SUS, via CONITEC. O técnico é apenas legítimo quando fruto de um procedimento formal e centralizado, de construção de significado de Estado. O que passou por este processo e, ainda assim, resulta em uma ação judicial, é caracterizado como parte da judicialização "devida".

O "não-técnico" passa a pertencer ao mundo das teses jurídicas. Os juristas, contudo, não tem amplo domínio do conteúdo deste novo "técnico", que precisa ser ensinado, explicado, traduzido, especialmente aos juízes. Nesse ponto, entram em cena tanto a atuação da procuradoria em parceria com as secretarias, elaborando pareceres que não podem ser tão "técnicos" assim, mas que permitam convencer o juiz de que os argumentos ali são mais "técnicos" que o dos médicos prescritores - por que incorporam não só as considerações de saúde pertinentes ao paciente mas também considerações de ordem pública. Este processo de tradução causa ruído - MS, HC e Agravo não têm o mesmo significado para gestores e procuradores. Não somente, existem diferenças institucionais, de capacidade de absorver efetivamente novos conhecimentos dos dois lados. Se a Secretaria "infla" seus órgãos de consultoria e assessoria jurídica, as PGEs recorrem às secretarias para conseguir o técnico, mas não alteram elas mesmas seus quadros para se tornarem mais multidisciplinares. Cabe à iniciativa individual dos procuradores em buscar conhecimentos fora de seu "quadrado", atividade desestimulada pelo grande volume de ações judiciais e altas taxas de sucesso dos 
demandantes. A solução é, assim, a padronização e massificação do tratamento das demandas, e a escolha estratégica de algumas delas para atuação mais detida.

Os NATs atuam como forma de legitimação extra sobre o que é considerado técnico pelas Secretarias. Ainda que detenham independência para inclusive opinar pelo tratamento fora da política, seus pareceres, em larga medida, dão o tom do tipo de defesa que se seguirá no processo. O NAT reduz os incentivos para que a defesa recorra a pareceres técnicos elaborados ou apresente teses divergentes às do núcleo, ainda que a posição institucional da maior parte das procuradorias seja a de contestar ou recorrer ainda assim, em razão do reconhecimento de repercussão geral e temas repetitivos pelo STF e STJ.

Além da atuação direta sobre processos, gestores e procuradores ainda se engajam em uma atuação de prevenção de litígios, com o uso de esferas administrativas ou convênios com Defensorias Públicas para impedir que demandas que possam ser prontamente internalizadas pela gestão se tornem ações judiciais. Uma das medidas mais bem-sucedidas resta nas esferas não judiciais de resolução de litígios, que dão mais voz aos gestores do SUS e à capacidade da política em adaptar o que prevê como "técnico" às demandas individuais. Se bem articuladas com as instâncias já processuais de gestão de demandas, como no caso da CRLS, estes espaços tem o condão de permitir que a interação do SUS com os pacientes sequer seja concebida como algo mediado por atores do sistema de justiça. Empoderam, assim, a administração pública. O caso de São Paulo, por outro lado, é bastante curioso pois, na tentativa de internalizar demandas administrativas inclusive por produtos não padronizados, apresenta uma posição contraditória da Secretaria diante do Judiciário e dos usuários, uma vez que oferece o medicamento antes da ação judicial, mas defende-se desta pretensão em juízo. Novamente, a integração entre as medidas pré-processuais e processuais se torna elemento chave para que estas estratégias possam, combinadas, gerar efeitos positivos em termos de gestão da judicialização.

Além de medidas pré-processuais, os comitês estaduais funcionam como um espaço adicional de interação, que solidifica a relação dos atores em rede, permitindo que o Judiciário se exponha continuamente a diferentes posições e possa, assim, ele mesmo também assumir o "técnico" da política como o argumento legitimo para decidir. A falta de estrutura própria destes espaços e o comparecimento apenas voluntário de muitos de seus atores limitam a capacidade de tornar o que se decide no âmbito dos comitês em medidas resolutivas ou mesmo com o 
condão de alterar posicionamentos jurisprudenciais amplamente desfavoráveis à administração pública.

Trabalhar em rede não é uma atividade trivial, sobretudo se exige mais do que interlocução mas respostas resolutivas. Estes atores, envolvidos com a gestão da judicialização, tornam as fronteiras entre a saúde e o direito permeáveis e cinzentas, um processo que tem ganhos em termos de inovação e responsividade às demandas sociais. Um efeito não esperado da judicialização é a aproximação institucional de atores inicialmente isolados entre si, que passam a avaliar os trabalhos uns dos outros. Existe neste processo um ganho em termos de transparência e compartilhamento de informações entre setores, algo que, indiretamente repercute sobre a sociedade. Como o fenômeno atrai ainda a atenção da academia e da grande mídia, o que estes atores fariam em um primeiro momento separados e isolados, sob escrutínio apenas de seus pares e lógicas específicas de trabalho, ganha acesso amplo e incentiva um debate maior sobre os limites da saúde pública, do direito e, especialmente do Estado - o debate põem em xeque o que se deve esperar como saúde e saúde pública e o que se deve exigir do direito e das instituições jurídicas. Não somente, a judicialização expõem gargalos, fraudes, o poder da indústria farmacêutica e as limitações também do mercado.

Estes ganhos não neutralizam, contudo, as perdas para o SUS associadas a judicialização. Como vimos, esta privilegia pacientes em melhores condições socioeconômicas, redistribui recursos orçamentários desproporcionalmente e, o que esta tese demonstrou, "infla" o corpo jurídico dos órgãos de saúde, realocando pessoal para setores de meio. Neste sentido, efetivamente, gera novos arranjos organizacionais e prioridades dentro do funcionamento normal das Secretarias, medidas que não passam pela formulação tradicional de políticas públicas dentro do SUS, que em geral envolvem tanto representantes de diferentes esferas da política pública como dos próprios usuários. Neste sentido, se a judicialização submete a administração pública ao escrutínio do judiciário e, em alguma medida, as decisões judiciais ao escrutínio da administração pública, a judicialização gera respostas políticas que são efetivamente criadas e implementadas por burocracias de meio, o que importa em reconhecer que serão respostas menos democráticas que aquelas geridas dentro do caminho descentralizado mas altamente participativo do processo decisório regular do SUS. 


\section{Bibliografia}

ALVES, Danielle Conte, BAHIA, Ligia, BARROSO, André Feijó. O papel da Justiça nos planos e seguros de saúde no Brasil. CAD. Saúde Pública, v. 25, n. 2, p. 279-290, 2009.

ARANTES, Rogerio Bastos. Judiciário e Política no Brasil. São Paulo: Iespe: Editora Sumaré: Fapesp: Educ, 1997.

. Ministério Público e política no Brasil. São Paulo: editora

Sumaré, 2002.

ARRETCHE, Marta. Estado Federativo e Políticas Sociais. Determinantes da Descentralização. Rio de Janeiro: Revan: São Paulo: FAPESP, 2000.

AUREA, Adriana Pacheco et al. Programas de assistência farmacêutica do Governo Federal: estrutura atual, evolução dos gastos com medicamentos e primeiras evidências de sua eficiência, 2005-2008. Texto para Discussão, Instituto de Pesquisa Econômica Aplicada (IPEA), 2011.

BARCELLOS, Ana Paula. Constitucionalização das políticas públicas em matéria de direitos fundamentais: o controle político-social e o controle jurídico no espaço democrático. In: SARLET, Ingo Wolfgang, TIMM, Luciano Benetti. Direitos Fundamentais, orçamento e “reserva do possível”. 2a . ed., Porto Alegre: Livraria do Advogado, 2010, p.101-132

BARROSO, Luís Roberto. Da Falta de Efetividade à Judicialização Excessiva: Direito à Saúde, Fornecimento Gratuito de Medicamentos e Parâmetros para a Atuação Judicial. Revista da Procuradoria-Geral do Estado do Rio Grande do Sul, vol. 31, n. 66, jul/dez 2007, p. 89-114.

BENEVIDES, Rodrigo Pucci de Sá, VIEIRA, Fabiola Sulpino. Os impactos do Novo Regime Fiscal para o financiamento do Sistema Único de Saúde e para a efetivação do direito à saúde no Brasil. Nota Ténica 28/2016. Brasília: IPEA, 2016. Disponível em: 
http://www.ipea.gov.br/portal/images/stories/PDFs/nota_tecnica/160920_nt_28_disoc.pdf (Acesso 13/01/2018).

BERGALlO, Paola. Argentina. "Courts and the right to health: Achieving Fairness Despite "Routinization" in Individual Coverage Cases?" In: GLOPPEN, S. e YAMIN, A.E., Litigating Health Rights. Cambridge: Harvard University Press, 2011, p. 43-75, 2011.

BIEHL, João, AMON, Joseph A., SOCAL, Mariana P., PETRYNA, Adriana. Between the court and the clinic: Lawsuits for medicines and the right to health in Brazil. Health and Human Rights, Vol. 14, No. 1, Junho 2012, pp. 36-52.

BILCHITZ, David. Is the Constitutional Court wasting away the rights of the poor? Nokotyana v Ekurhuleni Metropolitan Municipality. South African Law Journal, v. 127, n. 4, p. 591-605, 2010.

BOING, Alexandra et al. A judicialização do acesso aos medicamentos em Santa Catarina: um desafio para a gestão do sistema de saúde. Revista de Direito Sanitário, v. 14, n. 1, p. 82-97, 2013.

BORGES, D. C. L., UGÁ, M. A. D. Conflitos e impasses da judicialização na obtenção de medicamentos: as decisões de $1^{\mathrm{a}}$ instância nas ações individuais contra o estado do Rio de Janeiro. Cad. Saúde Pública Rio de Janeiro, v. 26, n. 1, p. 59-69, 2010.

BRASIL, "Base de Cálculo e aplicação mínima pelos entes federados em ações e serviços de saúde”, Ministério da Saúde, Secretaria Executiva. Brasília: 2016

BRASIL. Conselho Nacional de Secretários de Saúde. A Gestão do SUS. Brasília: CONASS, 2015 .

BRASIL. Conselho Nacional de Secretários de Saúde. Legislação Estruturante do SUS. Brasília: CONASS, 2011. 
BRASIL. Constituição Federal de 1988. Edição compilada. Brasília: 2018. Disponível em: http://www.planalto.gov.br/ccivil_03/constituicao/constituicaocompilado.htm

(Acesso 13/01/2018).

BRASIL. CONSULTORIA JURÍDICA DO MINISTERIO DA SAÚDE. Intervenção judicial na saúde pública. Advocacia Geral da União. Brasília: 2014. Disponível em: http://portalarquivos.saude.gov.br/images/pdf/2014/maio/29/Panorama-da-judicializa----o--2012---modificado-em-junho-de-2013.pdf (Acesso 13/01/2018)

BRASIL. Ministério da Saúde. Secretaria de Vigilância em Saúde. Programa Nacional de DST e Aids. O remédio via justiça: um estudo sobre o acesso a novos medicamentos e exames em HIV/aids no Brasil por meio de ações judiciais. Brasília: Ministério da Saúde, 2005.

BRASIL. Tribunal de Contas da União. Acórdão 1787/2017, Plenário, Processo n. 009.253/2015-7, Sessão: 16/8/2017.

CAETANO, Cristiana Ropelatto. Judicialização de Medicamentos. TELESSAÚDE, Santa Catarina: 2017. Disponível em: https://repositorio.ufsc.br/xmlui/handle/123456789/181555 (Acesso 13/01/2018).

CHIEFFI, Ana Luiza. Análise das demandas judiciais de medicamentos junto a Secretaria de Estado da Saúde de São Paulo à luz da política de assistência farmacêutica. Tese (Doutorado em Medicina Preventiva) - Faculdade de Medicina, Universidade de São Paulo, São Paulo, 2017. Disponível em: <http://www.teses.usp.br/teses/disponiveis/5/5137/tde-31072017130420/>. (Acesso em 13/01/2018).

CHIEFFI, Ana Luiza, BARATA, Rita Barradas. Judicialização da política pública de assistência farmacêutica e equidade. Cad. Saúde Pública, Rio de Janeiro, v. 25, n.8, p. 1839-1849, Agosto, 2009. 
CHIEFFI, Ana Luiza, SIQUEIRA, Paula Sue Facundo de. Judicialização da saúde no estado de São Paulo. Judicialização da saúde no Brasil. Organizadoras: Lenir Santos, Fernanda Terrazas, Campinas, SP: Saberes Editora, p. 267-301, 2014.

CONSELHO NACIONAL DE INCORPORAÇÃO DE TECNOLOGIAS NO SUS (CONITEC). "Histórico Institucional", publicado 20/05/2014, disponível em: http://conitec.gov.br/historico-institucional (Acesso 06/01/2018).

CONSELHO NACIONAL DE JUSTIÇA. Judicialização da saúde no Brasil: dados e experiência. Coordenadores: Felipe Dutra Asensi e Roseni Pinheiro. Brasília: Conselho Nacional de Justiça, 2015.

CONSELHO NACIONAL DE JUSTIÇA. Justiça em Números 2017: ano-base 2016. Brasília: CNJ, 2017.

COOPER, Carole. "Health rights litigation: cautious constitutionalism". In: GLOPPEN, S. e YAMIN, A.E., Litigating Health Rights. Cambridge: Harvard University Press, 2011, p. 190231.

CORRÊA, Luiza Andrade. Judicialização da política pública de educação infantil no Tribunal de Justiça de São Paulo. 2015. Dissertação (Mestrado em Direito do Estado) Faculdade de Direito, Universidade de São Paulo, São Paulo, 2015. doi:10.11606/D.2.2015.tde02122015-074746. Acesso em: 2017-12-04.

COUTO, Cláudio Gonçalves, ARANTES, Rogério Bastos. Constituição, governo e democracia no Brasil. Revista Brasileira de Ciências Sociais, v. 21, n. 61, p. 41-62, 2006.

DALLARI, Sueli. Aspectos particulares da chamada judicialização da saúde. Revista de Direito Sanitário, v. 14, n. 1, p. 77-81, 2013. 
DE OLIVEIRA, Vanessa Elias. Judiciário e privatizações no Brasil: existe uma judicialização da política?. Dados-Revista de Ciências Sociais, v. 48, n. 3, 2005.

DELEON, Peter. The Historical Roots of the Field. In: MICHAEL, Moran, REIN, Martin, GOODIN, Robert E (org.). The Oxford handbook of public policy. Oxford: Oxford University Press, 2008, p. 39-58.

DINIZ, Debora, ROBICHEZ DE CARVALHO MACHADO, Teresa, PENALVA, Janaina. A judicialização da saúde no Distrito Federal, Brasil. Ciência \& Saúde Coletiva, v. 19, n. 2, 2014.

DO VALLE, Gustavo Henrique Moreira, CAMARGO, João Marcos Pires. A audiência pública sobre a judicialização da saúde e seus reflexos na jurisprudência do supremo tribunal federal. Revista de Direito Sanitário, v. 11, n. 3, p. 13-31, 2011.

DRAIBE, Sônia Miriam. Avaliação da descentralização das políticas sociais no Brasil: saúde e educação fundamental. Informe Final do Projeto Estudios de Descentralización de Servicios Sociales da División de Desarrollo Econômico da CEPAL. 1997.

DYE, Thomas R. Understanding public policy. 14 edição. Pearson, 2013.

EASTON, David. The political system. New York: Knopf, 1993.

EPP, C. R. The rights revolution: Lawyers, activists, and supreme courts in comparative perspective. Chicago: University of Chicago Press, 1998.

ESCOREL, Sarah et al. História das políticas de saúde no Brasil de 1964 a 1990: do golpe militar à reforma sanitária. In: Políticas e sistema de saúde no Brasil. Fiocruz, 2012. p. 323363.

FANTI, Fabiola. Políticas de saúde em juízo: um estudo sobre o município de São Paulo. In: ENCONTRO ANUAL DA ANPOCS, 34., 2010, Águas de Lindóia. Disponível em: 
http://www.anpocs.com/index.php/papers-34-encontro/st-8/st17-7/1508-ffanti-justicacomum/file

FERRAZ, O. L. M., The right to health in the courts of Brazil: Worsening health inequalities? Health and Human Rights: An International Journal, 11(2): 33-45, 2009a.

, Harming the poor through social rights litigation: lessons from Brazil. South Texas Law Review, Vol.89 (No.7). pp. 1643-1668, 2011 b.

, "Brazil. Health Inequalities, Rights, and Courts: The Social Impact of the Judicialization of Health". In: GLOPPEN, S. e YAMIN, A.E., Litigating Health Rights. Cambridge: Harvard University Press, 2011, p. 76-102.

, Between Usurpation and Abdication? The Right to Health in the Courts of Brazil and South Africa, 2009b. Disponível em SSRN: http://ssrn.com/abstract=1458299 ou http://dx.doi.org/10.2139/ssrn.1458299 (Acesso 12/01/2018).

FERRAZ, Octavio Luiz Motta, VIEIRA, Fabiola Sulpino. Direito à proteção da saúde, recursos escassos e equidade: os riscos da interpretação judicial dominante. Dados Revista de Ciências Sociais, vol.52, n.1, 2009, pp. 223-251.

FERREIRA, Camila Duran et al.. Atuação do judiciário na concretização dos direitos sociais: Um estudo empírico do reconhecimento do direito à saúde como direito fundamental. In: Prêmio IPEA 40 anos: monografias premiadas. Brasília: IPEA, 2005.

FIGUEREDO, Mariana Filchtiner, SARLET. Ingo Wolfgang. "Reserva do possível, mínimo existencial e direito à saúde: algumas aproximações”. In: SARLET, Ingo Wolfgang, TIMM, Luciano Benetti (2010). Direitos Fundamentais, orçamento e "reserva do possível". 2a. ed., Porto Alegre: Livraria do Advogado, 2010, p. 13-50. 
FREEMAN, Richard. "Learning in public policy". In: MICHAEL, Moran, REIN, Martin, GOODIN, Robert E (org.). The Oxford handbook of public policy. Oxford: Oxford University Press, 2008, p. 367-388.

FRIEDRICH, Carl Joachim. Man and his government: An empirical theory of politics. New York: McGraw-Hill, 1963.

GARGARELlA, Roberto, DOMINGO, Pilar, ROUX, Theunis (Ed.). Courts and Social Transformation in New Democracies: an institutional voice for the poor? Ashgate Publishing, Ltd., 2006.

GAURI, V., BRINKS, D. M. Courting Social Justice. Judicial Enforcement of Social and Economic Rights in the Developing World. Cambridge: Cambridge University Press, 2008.

GLOPPEN, Siri, WILSON, Bruce, GARGARELLA, Roberto, KINANDER, Morten, \& SKAAR, Elin. Courts and power in Latin America and Africa. New York: Springer, 2016.

GLOPPEN, Siri. Litigation as a strategy to hold governments accountable for implementing the right to health, Health and Human Rights, vol. 10, n. 2, 2008, pp. 21-36.

GLOPPEN, Siri, ROSEMAN, Mindy Jane. "Introduction: Can litigation bring justice to health?". In: GLOPPEN, S. e YAMIN, A.E., Litigating Health Rights. Cambridge: Harvard University Press, 2011, p. 1-16, 2011.

GOMES, Dalila F., SOUZA, Camila Rufino, SILVA, Felipe Luiz da, PÔRTO, JULIANNA Alves, MORAIS, Indyara de Araújo, RAMOS, Maíra Catharina, \& SILVA, Everton Nunes da. Judicialização da saúde e a audiência pública convocada pelo Supremo Tribunal Federal em 2009: o que mudou de lá para cá?. Saúde em Debate, 38(100), 2014, 139-156. 
GOODIN, Robert E., REIN, Martin, MORAN, Michael. "The Public and its Policies". In: MICHAEL, Moran, REIN, Martin, GOODIN, Robert E (org.). The Oxford handbook of public policy. Oxford: Oxford University Press, 2008, p. 3-38.

HECLO, Hugh. Modern Social Politics in Britain and Sweden: From Relief to Income Maintenance. New Haven: Yale University Press, 1974.

HOFFMAN, F.F., BENTES, Fernando R.N.M.. "Accountability for Social and Economic Rights in Brazil". In: GAURI, Varun, BRINKS, Daniel M., Courting Social Justice. Cambridge: Cambridge University Press, 2008, p. 100-145

HOROWITZ, D.L. The Courts and Social Policy. Washington: The Brookings Institution, 1977.

HOWletT, Michael \& RAMESH, M. Studying Public Policy. Policy cycles and Policy Subsystems. 2a edição. Ontario: Oxford University Press, 2003.

INTERFARMA. Judicialização da Saúde na Prática. Intrafarma: São Paulo, 2016. Disponível em: https://www.interfarma.org.br/public/files/biblioteca/102-caderno-judicializacao-jul2016site.pdf (Acesso em 29/12/2017).

IPEA, Políticas sociais: acompanhamento e análise. Brasília: Ipea, 2016. Disponível em: http://www.ipea.gov.br/portal/images/stories/PDFs/politicas_sociais/20170519_bps24.pdf

JONES, Charles O. An Introduction to the study of public policy. Boston: Duxbury, 1977.

KAPISZEWSKI, Diana. High courts and economic governance in Argentina and Brazil. Cambridge: Cambridge University Press, 2012. 
LAMPREA MONTEALEGRE, Everaldo. Derechos en la práctica: jueces, litigantes y operadores de políticas de salud en Colombia (1991-2014). Ediciones Uniandes-Universidad de los Andes, 2015.

LASSWELL, Harold \& KAPLAN, Abraham. Power and Society. New Haven: Yale University Press, 1970.

LEITE, Silvana Nair, MAFRA, Ana Cristina. Que direito? Trajetórias e percepções dos usuários no processo de acesso a medicamentos por mandados judiciais em Santa Catarina. Revista Ciência \& Saúde Coletiva, v. 15, 2010.

LIMA, Nísia Trindade et al. A saúde na construção do Estado Nacional no Brasil: reforma sanitária em perspectiva histórica. In: Saúde e democracia: história e perspectivas do SUS. Fiocruz, 2005. p. 27-58.

LOTTA, Gabriela S., PIRES, Roberto Rocha Coelho, OLIVEIRA, Vanessa Elia de. "Burocratas de médio escalão: novos olhares sobre velhos atores da produção de políticas públicas". In: CAVALCANTE, Pedro Organizador, LOTTA, Gabriela (org.). Burocracia de médio escalão: perfil, trajetória e atuação. 2015.

LYNN, L. E.. Designing Public Policy: A Casebook on the Role of Policy Analysis. Santa Monica: Goodyear, 1980

MACHADO, Cristiani Vieira, LIMA, Luciana Dias, BAPTISTA, Tatiana Wargas de Faria. "Configuração Institucional e o Papel dos Gestores no Sistema Único de Saúde". In Políticas de saúde: organização e operacionalização do sistema único de saúde. Organizado por Gustavo Correa Matta e Ana Lucia de Moura. Pontes. Rio de Janeiro: EPSJV / Fiocruz, 2007.

MARCHETTI, Vitor, CORTEZ, Rafael. A judicialização da competição política: o TSE e as coligações eleitorais. Opinião Pública, v. 15, n. 2, p. 422-450, 2009. 
MARQUES, Silvia Badim, DALLARI, Sueli Gandolfi. Garantia do direito social à assistência farmacêutica no Estado de São Paulo. Revista de saúde pública, v. 41, n. 1, p. 101-107, 2007.

MENDES, Conrado Hubner. Direitos Fundamentais, Separação de Poderes e Deliberação. São Paulo: Saraiva, 20011.

MENICUCCI, Telma Maria Gonçalves. Público e privado na política de assistência à saúde no Brasil: atores, processos e trajetórias. Editora Fiocruz, 2007.

MESSEDER, A. M., OSORIO-DE-CASTRO, C. G. S., LUIZA, V. L. Mandados judiciais como ferramenta para garantia do acesso a medicamentos no setor público: a experiência do estado do Rio de Janeiro, Brasil. Cad. Saúde Pública. Rio de Janeiro, v. 21, n. 2, p. 525-534, 2005.

MINISTÉRIO DA SAÚDE. ORGANIZAÇÃO PAN-AMERICANA DA SAÚDE. Financiamento Público de Saúde. Série ECOS - Economia da Saúde para a Gestão do SUS. Brasília: Ministério da Saúde, 2013.

NAFFAH FILHO, Michel, CHIEFFI, Ana Luiza, CORREA, Maria Cecília MM. S-Codes: um novo sistema de informações sobre ações judiciais da Secretaria de Estado da Saúde de São Paulo. BEPA. Boletim Epidemiológico Paulista (Online), v. 7, n. 84, p. 18-30, 2010.

NOGUEIRA, Karina Pires, CAMARGO, Erika Barbosa. Judicialização da saúde: gastos Federais para o Sistema Único de Saúde (SUS) entre 2011-2014. Cadernos Ibero-Americanos de Direito Sanitário, v. 6, n. 2, p. 120-132, 2017.

NOVAES, Natália Fazano. Judicialização da saúde e assistência farmacêutica no pós-88: efeitos na administração pública municipal do Estado de São Paulo. Dissertação de Mestrado em Direito e Desenvolvimento. Escola de Direito da Fundação Getúlio Vargas. São Paulo: 2012. Disponível em: http://bibliotecadigital.fgv.br/dspace/bitstream/handle 
/10438/10297/Nat\%C3\%A1lia\%20Fazano\%20Novaes.pdf?sequence=1\&isAllowed=y (Acesso $13 / 01 / 2018)$

OLIVEIRA, Luciane Cristina Feltrin, ARAÚJO ASSIS, Marluce Maria, BARBONI, André René. Assistência farmacêutica no Sistema Único de Saúde: da Política Nacional de Medicamentos à atenção básica à saúde. Ciência \& Saúde Coletiva, v. 15, n. 3, 2010.

OLIVEIRA, V. E., ABRUCIO, F. L. Entre a política e a burocracia: a importância dos burocratas de nível médio para a produção de políticas públicas em saúde e educação. Artigo apresentado no $35^{\circ}$ Encontro Anual da ANPOCS, Caxambu, MG, 2011.

OLIVEIRA, Vanessa Elia de. Instituições, burocracias e produção de políticas públicas: o caso da política estadual de saúde. Artigo apresentando no $33^{\circ}$ Encontro Anual da ANPOCS, Caxambu, MG, 2009.

OLIVEIRA, Vanessa Elias de, MARCHETTI, Vitor. O Judiciário e o controle sobre as políticas públicas: a judicialização da educação no município de São Paulo. Artigo apresentado no $37^{\circ}$ Encontro Nacional da Anpocs, Caxambu, MG, 2013.

OLIVEIRA, Vanessa Elias, NORONHA, Lincoln. Judiciary-Executive relations in policy making: the case of drug distribution in the state of São Paulo. Brazilian Political Science Review, v. 5, n. 2, 2012.

PARMAR, Sharanjeet, WAHI, Namita. "India: Citizens, Courts and the Right to Health: Between Promise and Progress?”. In: GLOPPEN, S. e YAMIN, A.E., Litigating Health Rights. Cambridge: Harvard University Press, 2011, p. 155-189.

PEIXOTO, Felipe. Apresentação de slide: "O Impacto (Custos) das ordens judiciais no orçamento público da saúde. Secretaria de Saúde do Estado do Rio de Janeiro, 2017. Disponível em: http://slideplayer.com.br/slide/8624997/ (Acesso em 23/12/20170). 
PEPE, Vera Lúcia Edais et al. A judicialização da saúde e os novos desafios da gestão da assistência farmacêutica. Ciência \& Saúde Coletiva, v. 15, n. 5, 2010.

PETERS, B. G., American Public Policy. Chatham, New Jersey: Chatham House, 1986.

PIOLA, Sérgio Francisco et al. "Gasto tributário e conflito distributivo na saúde”. In: CASTRO, JA, SANTOS, CH, RIBEIRO, JAC. Tributação e equidade no Brasil: um registro da reflexão do Ipea no biênio 2008-2009, v. 2009, p. 351-374, 2010.

PIOLA, Sergio, PAIVA, Andrea, SÁ, Edvaldo, SERVO, Luciana. Financiamento Público da Saúde: uma história a procura de rumo. Texto para Discussão, Ipea. Brasília: Rio de Janeiro: Ipea, 2013.

RAMOS PEREIRA, Januária et al. Análise das demandas judiciais para o fornecimento de medicamentos pela Secretaria de Estado da Saúde de Santa Catarina nos anos de 2003 e 2004. Ciência \& Saúde Coletiva, v. 15, n. 3, 2010.

RODRIGUEZ-GARAVITO, Cesar. Beyond the Courtroom: The Impact of Judicial Activism on Socioeconomic Rights in Latin America, Texas Law Review vol. 89, no. 7, Junho, 2011, p. 1669-1698.

ROSENBERG, G. Hollow hope: Can courts bring about social change?, 2 ed, Chicago: University of Chicago, 2008.

SABEL, C. F., SIMON, W. H. Destabilization rights: how public law litigation succeeds, Harvard Law Review, p. 1015-1101, 2004.

SALAZAR, Andrea Lazzarini, GROU, Karina Bozola. A judicialização dos antirretrovirais no Brasil. In: Direitos Humanos e HIV/Aids: avanços e perspectivas para o enfrentamento da 
epidemia no Brasil. Ministério da Saúde, Secretaria de Vigilância em Saúde, Programa Nacional de DST e Aids. Brasília: Ministério da Saúde, 2008, p. 43.

SANTOS, Alethele de Oliveira, DELDUQUE, Maria Célia, \& MENDONÇA, Ana Valéria Machado. Os discursos na Audiência Pública da Saúde e seu impacto nas decisões do Supremo Tribunal Federal: uma análise à luz da teoria dos sistemas sociais. Saúde e Sociedade, 24, (1), p.184-192, 2015.

SÃO PAULO, Secretaria de Saúde do Estado de São Paulo. Protocolo do Estado de São Paulo de Diagnóstico Tratamento e Encaminhamento de Pacientes com Transtorno do Espectro Autista (TEA), ${ }^{a}$ edição. São Paulo: SEDPcD, 2013.

SARLET, Ingo Wolfgang. A Eficácia dos Direitos Fundamentais. 6 ${ }^{a}$ ed., Porto Alegre: Livraria do Advogado, 2006.

SCHEFFER, M., SALAZAR, A.L., GROU, K.B. O Remédio via Justiça: um estudo sobre o acesso a novos medicamentos e exams em HIV/AIDS no Brasil por meio de ações judiciais. Brasília: Ministério da Saúde, 2005.

SCHEFFER, Mario. Coberturas assistenciais negadas pelos planos e seguros de saúde em ações julgadas pelo Tribunal de Justiça do Estado de São Paulo. Revista de Direito Sanitário, v. 14, n. 1, p. 122-131, 2013.

SCHEINGOLD, S.A. The Politics of Rights. New Haven, Conn.: Yale University Press, 1974.

SILVA, Hudson P., PETRAMALE, Clarice A., ELIAS, Flavia TS. Avanços e desafios da política nacional de gestão de tecnologias em saúde. Revista de Saúde Pública, v. 46, n. spe, p. 83-90, 2012.

SILVA, Raquel da Silveira Amprozio. Análise da judicialização da assistência farmacêutica no Rio Grande do Sul - a coletividade no banco dos réus: uma avaliação da $7^{\mathrm{a}}$ 
Coordenadoria Regional de Saúde. Tese de Mestrado Profissional. Universidade Federal do Rio Grande do Sul. Faculdade de Medicina. Programa de Pós-Graduação em Ensino na Saúde, 2014.

SILVA, Virgílio Afonso da, TERRAZAS, Fernanda. Claiming the Right to Health in Brazilian Courts: The Exclusion of the Already Excluded. Law \& Social Inquiry, vol. 36, no. 4, 2011, pp. $825-853$.

SILVA, Virgilio Afonso da. Direitos Fundamentais. Conteúdo essencial, Restrições e Eficácia. São Paulo: Melhoramentos, 2009.

SOARES SANTOS, Isabela, DOMINGUEZ UGÁ, Maria Alicia, PORTO, Silvia Marta. O mix público-privado no Sistema de Saúde Brasileiro: financiamento, oferta e utilização de serviços de saúde. Ciência \& Saúde Coletiva, v. 13, n. 5, 2008.

SOUZA, Anderson Monteiro. A atuação em rede de instituições governamentais na resolução de conflitos sobre demandas sanitárias no Rio de Janeiro. Dissertação de Mestrado Profissional defendida junto a Escola de Administração Pública e Empresas da Fundação Getúlio Vargas. Rio de Janeiro, 2016.

SOUZA, Celina. Políticas públicas: uma revisão da literatura. Sociologias, Porto Alegre, n. 16, p. $20-45,2006$.

TATE, C. Neal, VALLINDER, Torbjorn (Ed.). The global expansion of judicial power. New York: NYU Press, 1995.

TAYLOR, Matthew M. O judiciário e as políticas públicas no Brasil. DADOS-Revista de ciências sociais, v. 50, n. 2, 2007.

TAYLOR, Matthew M.. Judging policy: courts and policy reform in democratic Brazil. Stanford University Press, 2008. 
TEIXEIRA, Mariana Faria. Criando alternativas ao processo de judicialização da saúde: o sistema de pedido administrativo, uma iniciativa pioneira do estado e município do Rio de Janeiro. Dissertação de Mestrado defendida junto à Escola Nacional de Saúde Publica Sergio Arouca. Rio de Janeiro: 2011.

TIBYRIÇÁ, Renata Flores. Da legalidade à realidade: o uso do serviço público de educação para pessoas com transtorno do espectro do autismo na cidade de São Paulo. 2014. 112 f. Dissertação (Mestrado em Psicologia) - Universidade Presbiteriana Mackenzie, São Paulo, 2014.

TOMA, Tereza Setsuko et al. Estratégias para lidar com as ações judiciais de medicamentos no estado de São Paulo. Cadernos Ibero-Americanos de Direito Sanitário, v. 6, n. 1, p. 35-54, 2017.

TORRES, Ricardo Lobo (1989). O Mínimo Existencial e os Direitos Fundamentais, Revista de Direito Administrativo, 177: 29-49, 1989.

TRAVASSOS, Cláudia et al. Desigualdades geográficas e sociais na utilização de serviços de saúde no Brasil. Ciência \& Saúde Coletiva, v. 5, n. 1, 2000.

VASCONCELOS, Natália Pires de. Judiciário e orçamento público: considerações sobre o impacto orçamentário de decisões judiciais. Dissertação (Mestrado em Direito do Estado) Faculdade de Direito, Universidade de São Paulo, São Paulo, 2015. Disponível em: <http://www.teses.usp.br/teses/disponiveis/2/2134/tde-03082016-144546/> . Acesso em: 201712-03.

VENTURA, Miriam et al. Judicialização da saúde, acesso à justiça e a efetividade do direito à saúde. Physis, Rio de Janeiro, v. 20, n. 1, p. 77-100, 2010. 
VENTURA, Miriam. O processo decisório judicial e a assessoria técnica: a argumentação jurídica e médico-sanitária na garantia do direito à assistência terapêutica no Sistema Único de Saúde. Tese de Escola Nacional de Saúde Pública Sergio Arouca, Rio de Janeiro, 2012. Disponível em: http://bvsms.saude.gov.br/bvs/publicacoes/premio2012/douto rado/Miriam\%20Ventura\%20da\%20Silva.pdf (Acesso 29/12/2017).

VERISSIMO, Marcos Paulo. A Constituição de 1988, Vinte Anos Depois: Suprema Corte e Ativismo Judicial “À Brasileira”, Revista Direito GV, n. ${ }^{\circ}$ 8, São Paulo: FGV, jul. a dez. 2008.

VIEIRA, Fabiola Sulpino, ZUCCHI, Paola. Distorções causadas pelas ações judiciais à política de medicamentos no Brasil. Rev. Saúde Pública, São Paulo, v. 41, n. 2, p. 214-222, abr. 2007

VIEIRA, Oscar Vilhena. Supremocracia, Revista Direito GV, v. 4, n. 2, p. 441-463, 2008.

WANG, Daniel W., FERRAZ, Octavio L. M., Atendendo os mais necessitados? Acesso à justiça e o papel dos defensores e promotores públicos no litígio sobre direito à saúde na cidade de São Paulo. Sur: Revista Internacional de Direitos Humanos, v. 10, n. 18, 2013.

WANG, Daniel W. L. et al., Os impactos da judicialização da saúde no município de São Paulo: gasto público e organização federativa. Revista de Administração Pública-RAP, v. 48, n. 5, 2014.

WANG, Daniel W. L., Right to Health litigation in Brazil: The problem and the institutional responses. Human Rights Law Review, v. 15, n. 4, p. 617-641, 2015.

. Poder Judiciário e participação democrática nas políticas públicas de saúde. 2009. Dissertação (Mestrado em Direito do Estado) - Faculdade de Direito, Universidade de São Paulo, São Paulo, 2009. 
WANG, Daniel, VASCONCELOS, Natália, Adjudicação de direitos e escolhas políticas na assistência social, Novos Estudos CEBRAP, Edição 103, Volume 34, N. 3, Novembro de 2015. YAMIN, Alicia Ely. Power, suffering, and courts: Reflections on promoting health rights through judicialization. In: GLOPPEN, S. e YAMIN, A.E., Litigating Health Rights. Cambridge: Harvard University Press, 2011, p. 333-372.

YAMIN, Alicia Ely, PARRA-VERA, Oscar, GIANELLA, Camila. Judicial Protection of the Right to Health: An Elusive Promise? In: GLOPPEN, S. e YAMIN, A.E., Litigating Health Rights. Cambridge: Harvard University Press, 2011, p. 103. 